\title{
Advances in Teaching and Learning Technologies
}

\author{
Olga B. Scrivner \\ Indiana University \\ obscrivn@indiana.edu
}

\author{
Conan C. Albrecht \\ Brigham Young University \\ doconix@gmail.com
}

\author{
Gove Allen \\ Brigham Young University \\ gove@byu.edu
}

The rapidly changing technological environment is deeply converging with many aspects of education. From omnipresent mobile devices and immersive technologies to popular social media and massive online open courses, these technologies have transformed the dynamics in teaching and learning. The 2016 K-12 Horizon Report has identified several key developments (e.g., makerspaces, online learning, virtual reality) leading to changes in collaborative "learning strategies; the organization of teachers' work; and the arrangement and delivery of content" [1, p.35]. Despite the great potential of technology, educators must embrace the great responsibility for designing new course modules, developing new metrics, and evaluating technology impact on learners. Furthermore, technology is rapidly transforming industry, creating a gap between curriculum and skills taught and job market demands. [2]. There is a need for collaborative solutions between industry and institutions for reshaping educational landscape to accommodate the demands of job market.

In this minitrack, we explore multiple perspectives of learning technologies, from their design, implementations, and evaluation (e.g. VR design and learning analytics) to their broad impact on society, such improving refugees' literacy. Four themes have emerged from the fifteen papers accepted to the minitrack: a) innovative approaches, b) metrics and evaluation, c) collaboration and curriculum, and d) design and visualization. The first theme addresses the question of students' engagement and retention. The implementation of social platform as a peer learning environment helps to improve students' engagement. Similarly, the research on virtual learning environments demonstrates different outcome levels based on the technology type (VR, 3D, 2D) and shares the design recommendations. The use of Personal Smart Assistants is another learning technology capable of improving students' learning success. Finally, the serious gaming approach is thought as a learning tool to decrease engagement gap. The second theme focuses on modeling and evaluation for large classes. One study develops a recommender system with learning analytics scores to measure message quality of large online classes. Others evaluate the effectiveness of various learning methods on large classes. The third theme is centered on collaboration and curriculum. Industry-university collaborations are viewed as a powerful learning tool. Curriculum development is also seen as an impactful instrument helping not only in business school but also improving refugees' literacy. The fourth theme incorporates various aspects of visualization. Learning analytics dashboards are designed from a student perspective as a tool to improve students' performance. On the other hand, designing dashboards by an educator has the potential to improve pedagogical practices. Finally, the development of visualization for programming languages can help retain the learned knowledge.

\section{References}

[1] A. S. Becker, A. Freeman, Giesinger H., M. Cummins, and B. Yuhnke, "The NMC/CoSN Horizon Report: 2016 K-12 Edition," Austin, Texas, 2016.

[2] K. Börner et al., "Skill discrepancies between research, education, and jobs reveal the critical need to supply soft skills for the data economy.," Proc. Natl. Acad. Sci. U. S. A., vol. 115, no. 50, pp. 12630-12637, Dec. 2018. 